\title{
Exploratory pilot study of driving perceptions among OIF/OEF Veterans with mTBI and PTSD
}

\author{
Elizabeth "Lisa” M. Hannold, PhD; ${ }^{*}$ Sherrilene Classen, PhD, MPH, OTR/L, FAOTA ; ${ }^{2-3}$ Sandra Winter, PhD, \\ OTR/L; ${ }^{1-3}$ Desiree N. Lanford, MOT, OTR/L, CDRS; ${ }^{2-3}$ Charles E. Levy, MD ${ }^{1-4}$ \\ ${ }^{1}$ Rehabilitation Outcomes Research Center, Research Enhancement Award Program, North Florida/South Georgia \\ (NF/SG) Department of Veterans Affairs Health System (VAHS), Gainesville, FL; ${ }^{2}$ Institute for Mobility, Activity, and \\ Participation, University of Florida College of Public Health and Health Professions, Gainesville, FL; ${ }^{3}$ Department of \\ Occupational Therapy, University of Florida College of Public Health and Health Professions, Gainesville, FL; \\ ${ }^{4}$ Physical Medicine and Rehabilitation Service, NF/SG VAHS, Gainesville, FL
}

\begin{abstract}
Veterans of Iraq and Afghanistan may experience driving-related challenges postdeployment, including more atfault crashes. Causes may include defensive driving tactics learned for combat zones and consequences of traumatic brain injuries (TBIs) and posttraumatic stress disorder (PTSD). Tailoring driver interventions to meet Veterans' needs requires an understanding of their driving perceptions. We explored the driving perceptions of five combat Veterans (4 men, 1 woman) with mild TBI and PTSD using grounded theory methods. Veterans participated in single, semistructured interviews during a comprehensive driving evaluation. Interviews were digitally recorded, transcribed verbatim, verified, and imported into NVivo 8 software for coding and analysis. Veterans were insightful about driving and identified specific environmental triggers for anxious driving, speeding, and road rage. Veterans used strategies to moderate driving behaviors, but continued to drive aggressively. Themes were used to develop a conceptual framework of driving postdeployment, laying the foundation for intervention studies.
\end{abstract}

Key words: Afghanistan, automobile driving, blast injuries, brain injuries, combat disorders, Iraq, occupational therapy, qualitative research methods, stress disorders/posttraumatic, Veterans.

\section{INTRODUCTION}

Driving consists of a series of complex skills that may be affected by personal (e.g., vision, ability to con- centrate), social (e.g., presence of passengers, cultural standards for driving), and environmental (e.g., road and weather conditions) factors and/or a combination of all the aforementioned. The freedom to drive is closely tied to an individual's quality of life (QOL) [1]. Driving facilitates community integration through access to work, school, and social activities as well as providing a sense of personal independence and autonomy [1]. Recent studies report that returning combat Veterans from Operation

\footnotetext{
Abbreviations: IED $=$ improvised explosive device, IRB = institutional review board, $\mathrm{mTBI}=$ mild traumatic brain injury, MMSE = Mini-Mental State Examination, NF/SG = North Florida/South Georgia, OT/CDRS = occupational therapist/ certified driver rehabilitation specialist, $\mathrm{OEF}=$ Operation Enduring Freedom, OIF = Operation Iraqi Freedom, PTSD = posttraumatic stress disorder, $\mathrm{PI}$ = principal investigator, QCo-I = qualitative co-investigator, $\mathrm{QOL}=$ quality of life, $\mathrm{SE}=$ standard error, TBI = traumatic brain injury, VA = Department of Veterans Affairs, VAHS = VA Health System, VBIED = vehicleborne improvised explosive device.

*Address all correspondence to Lisa M. Hannold, PhD; Research Health Scientist, RORC-REAP, 151-B, NF/SG VAHS, 1601 SW Archer Rd, Gainesville, FL 32608; 352376-1611, ext 4947; fax: 352-271-4540.

Email: lisa.hannold@va.gov

http://dx.doi.org/10.1682/JRRD.2013.04.0084 
Iraqi Freedom (OIF) and Operation Enduring Freedom (OEF) are experiencing driving-related challenges that affect their community reintegration [2-6]. These findings emphasize that when driving is impaired, the risk of crashes, injuries, or deaths increases. However, not being able to drive may also threaten independence, community integration, and QOL [1,7].

Lew et al. reported that motor vehicle crashes are among the top four causes of injury, disability, hospitalization, and outpatient visits among returning OIF/OEF Veterans and a leading cause of death among Army servicemembers within the first year postdeployment [4]. In 2010 and 2011, transportation accidents were only surpassed by suicide as a leading cause of death among Active Duty servicemembers [8]. Furthermore, these Veterans may be predisposed to driving difficulties by the carryover of Battlemind* driving strategies and tactics acquired through military training and reinforced in theater $[4,9]$. These tactics include speeding, making abrupt changes in course, rapid lane changes, not wearing seatbelts, not yielding right of way, and straddling the center line. In combat, these tactics are used to reduce vulnerability to attacks and explosions. Unfortunately, the survival driving habits of the war zone may contribute to increased crash, injury, and fatality risks for the driver, passengers, and other road users when applied to civilian environments [4-5]. The United Services Automobile Association, an insurer of military servicemembers and Veterans, examined records from 2007 to 2010 and found soldiers in the first 6 months postdeployment had a 13 percent increase in at-fault crashes [10]. Addressing driving issues of returning Veterans can contribute to crash and injury prevention and facilitate community reintegration efforts [7]. In one study, 35 percent of the Veterans surveyed identified risky driving as a challenge to community reintegration - a challenge they were interested in overcoming with interventions to improve driving safety [11].

In addition to driving tactics learned in combat, cognitive compromise and emotional dysregulation related to traumatic brain injury (TBI), posttraumatic stress disorder (PTSD), and physical impairment including ampu-

* The term Battlemind is defined as the soldier's inner strength to face fear and adversity in combat with courage and compromises, selfconfidence to take risks, ability to handle future challenges, mental toughness, and ability to overcome setbacks and maintain positive thoughts during times of adversity [9]. tation, burns, or chronic pain [12] all have the potential to affect safe driving of servicemembers upon return to civilian life. Previous studies using survey or self-report methods, and including returning OIF/OEF Veterans, have identified aggressive, unsafe, or dangerous driving as issues for those with PTSD [13], TBI [3], or both conditions [4-5,11,14-15]. TBI leads to cognitive, physical, behavioral, emotional, visual, and perceptual deficits [16], which can result in unsafe vehicle operation [3]. As of 2012, the Defense Medical Surveillance System and Theater Medical Data Store reports that more than 266,810 servicemembers sustained TBIs between 2000 and 2012, including both U.S. and overseas forces [17].

Within the Department of Veterans Affairs (VA) Health System (VAHS), Veterans who screen positive for mild TBI (mTBI) have high rates of co-occurring PTSD [18-19]. For this article, we define PTSD using the American Psychiatric Association's six diagnostic criteria for PTSD, which include exposure to a traumatic event, intrusive recollections, avoidant/numbing symptoms, hyperarousal symptoms, symptom duration lasting more than 1 month, and impairment of function [20]. In 2010, an estimated 408,167 Veterans treated at VA medical centers and clinics had a primary or secondary diagnosis of PTSD [19]. Overlap exists among the symptoms of PTSD and those of mTBI [21], and these symptoms contribute to road rage, anxious driving, and other forms of risky driving [4,13-14]. The previous studies offer findings about the impact of mTBI and/or PTSD on driving behaviors. In tailoring interventions to meet Veterans' unique needs, more comprehensive information is needed about Veterans' experiences of driving while deployed and in civilian life. Classen et al. used a mixed-methods design pilot study to address this knowledge gap [5]. Using quantitative methods, Classen et al. examined errors in simulated driving performance in 18 postdeployment combat Veterans with mild to moderate TBI and PTSD and 20 nondisabled control subjects. Overall, combat Veterans made more critical driving errors than did control participants, including over-speeding $(t$ [17.3] $=$ 4.095, $p=0.001$, standard error $[\mathrm{SE}]=0.708$ ) and adjustment-to-stimuli $(t[17]=2.380, p=0.03, \mathrm{SE}=0.14)$ errors. This article focuses on the qualitative portion of the pilot study. Primary study details appear in the "Methods" section.

Extending the work of the quantitative portion of the pilot study [5], our research questions were (1) How do Veterans describe their current driving habits, behaviors, and experiences?, (2) What do Veterans identify as influences on their driving habits and behaviors?, (3) How 
insightful are Veterans regarding their driving behavior?, and (4) What, if any, driving strategies do Veterans report that are related to Battlemind driving, mTBI, or PTSD issues?

\section{METHODS}

\section{Design}

We used qualitative research methods, specifically grounded theory [22-24], to answer our research questions, guide data analyses, and develop an initial conceptual framework. In grounded theory, research questions and theory are produced inductively from the data [22-24].

\section{Sample}

A convenience subsample of five combat Veterans from the Classen et al. study of driving errors $(N=18)$ [5] participated in a driving-focused interview, described subsequently. Inclusion criteria for the Classen et al. study included (1) history of OIF or OEF deployment, (2) receiving care from the North Florida/South Georgia (NF/SG) VAHS, (3) diagnosis of mTBI or PTSD, (4) ability to drive before the injury or condition, (5) valid driver's license or eligible for driver's license, (6) Mini-Mental State Examination (MMSE) score of at least 24 of 30, (7) community dweller, (8) potential for following driving safety recommendations (MMSE > 24), (9) ability to travel to the testing site, and (10) able to participate in driving evaluation battery. Exclusion criteria included (1) severe psychiatric (e.g., psychoses) or physical conditions (e.g., missing limbs) that would preclude full participation, (2) psychotropic medications that could negatively affect mental or physical functioning because of side effects, (3) moderate or severe TBI that could preclude participation, (4) pregnant, or (5) employed by VA. We present sample demographics in the Table.

\section{Data Collection, Coding, and Analyses}

An occupational therapist/certified driver rehabilitation specialist (OT/CDRS) conducted a comprehensive driver evaluation with 18 Veteran participants from the Classen et al. study [5]. The evaluation included a driving behavior assessment; clinical tests of vision, cognition, motor skills, and sensory skills; and an evaluation of driving errors made on a driving simulator. During driving behavior assessments, Veterans shared compelling stories about driving. To capture this data, we submitted an institutional review board (IRB) revision to conduct/ record a qualitative interview as part of the assessment. Prior to IRB approval, we collected data from 13 participants. Following IRB approval, a convenience sample of five participants remained and we interviewed each of them.

The OT/CDRS conducted single, in-person, semistructured interviews at intake: on the same day as, and just before, the driving simulation test. The research team developed the interview guide (Figure 1). The OT/CDRS digitally recorded all interviews and documented relevant statements and behaviors using handwritten notes. A trained research assistant transcribed the recordings and notes verbatim, and the OT/CDRS verified them for accuracy. The qualitative co-investigator (QCo-I) imported the verified transcripts into NVivo 8 Qualitative Data Analysis Software (QSR International Pty Ltd; Victoria, Australia; version 8, 2008) for coding. The QCo-I coded and reviewed the data line by line to identify prominent themes, highlighting relevant text and assigning representative codes. The QCo-I developed an initial coding scheme based on the first transcript and revised it as the analyses progressed. The final coding scheme, reviewed with the principal investigator (PI; S. Classen), provided the primary components of our preliminary conceptual framework.

We used the constant comparative method to systematically compare new data to text/data previously categorized at specific codes [22]. This method allowed the identification of thematic similarities and differences, patterns, and relationships. During analysis, we drew visual representations to illustrate emerging constructs and relationships. These representations evolved into the preliminary conceptual framework presented with our findings (Figure 2).

We refined the initial framework by comparing our themes to relevant theories in occupational therapy, traffic safety, and psychology and to relevant research findings on OIF/OEF Veterans, mTBI, PTSD, and driving rehabilitation. This process aided us in reconceptualizing our operational definitions of aggressive driving, anxious driving, road rage, and Battlemind driving. We briefly summarize these theories in the "Findings" section.

\section{Efforts to Ensure Rigor}

We documented all coding and analysis decisions to allow others to confirm our findings-a criterion for evaluating rigor in qualitative research [25]. Specifically, we recorded a definition, date, and rationale for each code added to the framework as well as dates and explanations 
Table.

Demographics of participants $(N=5)$.

\begin{tabular}{|c|c|}
\hline Characteristic & Frequency or Mean \\
\hline \multicolumn{2}{|l|}{ Sex, $n(\%)$} \\
\hline Male & $4(80)$ \\
\hline Female & $1(20)$ \\
\hline \multicolumn{2}{|l|}{ Race, $n(\%)$} \\
\hline White & $4(80)$ \\
\hline High School Graduate & $2(40)$ \\
\hline Some College & $3(60)$ \\
\hline \multicolumn{2}{|l|}{ Lives With, $n(\%)$} \\
\hline Spouse or Partner & $2(40)$ \\
\hline Other Family & $2(40)$ \\
\hline No & $0(0)$ \\
\hline \multicolumn{2}{|l|}{ Reported mTBI diagnosis, $n$ (\%) } \\
\hline Yes & $5(100)$ \\
\hline No & $0(0)$ \\
\hline Reported Days Driving per Week, Mean \pm SD (range) & $6.2 \pm 1.79(3-7)$ \\
\hline Reported Violations/Citations in Last 3 Yr, Mean \pm SD (range) & $1.8 \pm 1.10(0-3)$ \\
\hline Reported Crashes in Last 3 Yr, Mean \pm SD (range) & $0.2 \pm 0.45(0-1)$ \\
\hline \multicolumn{2}{|l|}{ Reported Driving Avoidance, $n(\%)$} \\
\hline Rush Hour & $5(100)$ \\
\hline Rain & $3(60)$ \\
\hline Interstate/Expressway & $2(40)$ \\
\hline
\end{tabular}

for renaming, redefining, or deleting existing codes. After the QCo-I completed the initial coding scheme, she presented initial themes, coding schemes, and findings to the PI and a local community reintegration research interest group for auditing. The auditing process continued at each stage of analysis. Coauthors (S. Classen and S. Winter) reviewed the interview transcripts, coding records, and conceptual framework. Discrepancies in coding or analytical interpretations were discussed among the authors to reach a consensus and then revised accordingly.

\section{FINDINGS}

Several broad categories, specific themes, patterns, and relationships emerged. We used our findings, rele- vant theories, and the literature to construct a preliminary conceptual framework (Figure 2) that illustrates factors and processes underlying driving behavior among Veterans with mTBI and PTSD. To provide a context for understanding the framework, we first present key findings by describing the framework's thematic components. We summarize our findings through presentation of the conceptual framework.

\section{Themes, Patterns, and Relationships}

\section{Racers and Grandmas: Implications for Driver Identity}

Within the category of driver-related factors, a primary theme to emerge from our data was driver identity-a Veteran's characterization of himself or herself as a driver. While discussing changes in their driving from 


\section{Driving Behavior Assessment}

\section{Q.1 Do you have any concerns about your driving?}

Q.2 Does anything make you anxious/nervous while you are driving?
Q.2a If yes, please describe this thing(s) and/or situation(s) that make you nervous:

Q.3 Do you avoid any maneuvers, things, or locations?

Q.3a If yes, please describe:

\section{Q.4 Do you tend to speed a lot?}

\section{Q.4a If yes, describe the situation(s) in which you speed:}

\section{Q.5 Do you experience road rage?}

\section{Q.5a Describe the things/situations that trigger your road rage:}

Q.6 Have you acquired any new driving behaviors since coming back from the war?

\section{Q.6a If yes, please explain:}

\section{Q.7 Do you have any additional comments to share?}

Figure 1.

Semistructured interview guide questions.

pre- to postdeployment, some Veterans described themselves in terms of social roles. For example, Veteran 24 shared, "I build race engines ... in my truck. I've done ... I've been racing since I was little. Started out [with] gocarts, then I got into . . . uh, stock car. But my wife made me give all that up. So I just build my own stuff for my own truck." Veteran 24 perceived himself as a "racer." He was knowledgeable about building race engines and had driven racing vehicles since he was a child. Although his wife restricted his racing activities, it appeared that Veteran 24 maintained a "racer" identity. Given that Veteran 24 identified few changes in his driving following deployment, it is possible that his military training in combat-zone driving reinforced his long-standing aggressive driving habits.

Veteran 23, our only female participant, provided a second example of driver identity. While describing changes in her driving postdeployment, she shared "My husband used to call me a 'grandma.' And I was never allowed to drive because I would drive the speed limit or five [miles] under. And I would drive so carefully.” Unlike Veteran 24, Veteran 23 implied that her sense of driver identity changed postdeployment. Although she drove slowly and cautiously, like a "grandma," prior to service, Veteran 23 openly admitted that she now drives faster and more recklessly. When discussing that traffic 
makes her anxious, Veteran 23 explained, "I get so [with emphasis] overwhelmed, I drive crazy [small laugh].”

\section{Anxious Driving Triggers, Speeding Triggers, and Road Rage Triggers}

Our data revealed three categories of events or "triggers" that stimulated reactions from Veterans: anxious driving triggers, speeding triggers, and road rage triggers. We defined anxious driving triggers, based on Veterans' accounts, as events that induce nervousness when driving. We defined speeding triggers as factors the Veterans' associated with exceeding the speed limit. We defined road rage triggers as driving encounters that Veterans' reported led to anger (sometimes extreme), aggressive driving, and potentially violent behavior. Figure 3 summarizes the anxious driving triggers, speeding triggers, and road rage triggers identified by participants.

\section{Anxious Driving Triggers}

Highways and traffic. Concern about driving on busy highways or in heavy traffic was a recurrent theme in our data. When discussing situations that make her nervous while driving, Veteran 23 explained, "I get overwhelmed sometimes if there's just like a lot of traffic. I feel like I'm trapped . . . . I don't go places where there's a lot of traffic, or a lot of people. I try to avoid 'em.” Veteran 23's feeling of being "trapped" by traffic and crowds implied a need to get away from something or someone. Although Veteran 23 did not overtly associate her fears of traffic (and crowds) with a specific threat, her fears were consistent with hyperarousal symptoms associated with PTSD [26].

Loud or distracting noises. Data further indicated that loud or distracting noises provoked anxiety and, in some cases, triggered PTSD-related symptoms. For example, Veteran 24 recalled having a flashback after he mistook a tire exploding on a nearby tractor-trailer to be an improvised explosive device (IED). When asked what happened during the flashback, Veteran 24 replied, "I dropped to the third gear, stomped the gas, and ... went about 300 yards, and then locked the brakes up in the middle of the road on [a major interstate]. So the Army referred me to behavioral health . . . . I did what I was trained to do in Iraq." For Veteran 24, the sound of an exploding tire immediately brought him back to the war zone, and he drove accordingly. Our data also revealed that common noises, such as talkative passengers, distracted Veterans while driving and added to their anxiety.
Certain vehicles. Data indicated that encountering certain types of vehicles while on the road caused Veterans to become anxious. In the following example, Veteran 26 related how his combat-related experiences with vehicle-borne improvised explosive devices (VBIEDs) affect his driving now:

Uh, vehicles that were typically used for you know ... . VBIEDs kind of make me nervous sometimes. Like, I get a little more leery around them. Like if uh . . . thank God we don't have too many Opels or Bongo trucks here .... . Opel's a car company and a Bongo truck is like a little, crappy looking, little flat-bed truck that they use all over the place over there. . . like I said, certain vehicles you would use more for like VBIEDs, such as like the smaller sedans and like uh, SUVs, I get a little bit more ... observant around those kind of vehicles.

Although Veteran 26 acknowledged that few Opels and Bongo trucks are found in the United States, he admitted that if he encounters vehicles that resemble them while driving, he becomes more vigilant. Veteran 26's vigilance was accompanied by feelings of stress as he perceived the threat of explosives - an unlikely threat in his current driving environment.

\section{Speeding Triggers}

Speeding was common among Veterans in our sample, and several themes signifying speeding triggers emerged, including environmental factors such as intersections and overpasses. The data, however, also indicated that an increase in Veterans' arousal levels and, in one case, functional limitations due to injury (e.g., decreased ability to sense gas pedal and move leg), may further contribute to speeding.

Need to get off the road. Feeling the need to get off the road was a common theme. Given the anxiety that accompanied driving, it is not surprising that our participants sought to minimize their time on the road. When discussing her tendency to speed, Veteran 23 explained, "I just want to get there [destination] . . . as quick as possible. If I have to drive long distances I speed a lot.”

Hyperarousal versus inattention. Our data provided evidence that Veterans linked both hyperarousal and inattention to speeding. Hyperarousal, including hypervigilance, is a symptom of PTSD [26]. Hyperarousal is a persistent state of elevated arousal that includes symptoms of hypervigilance (overalertness to the presence of threats 


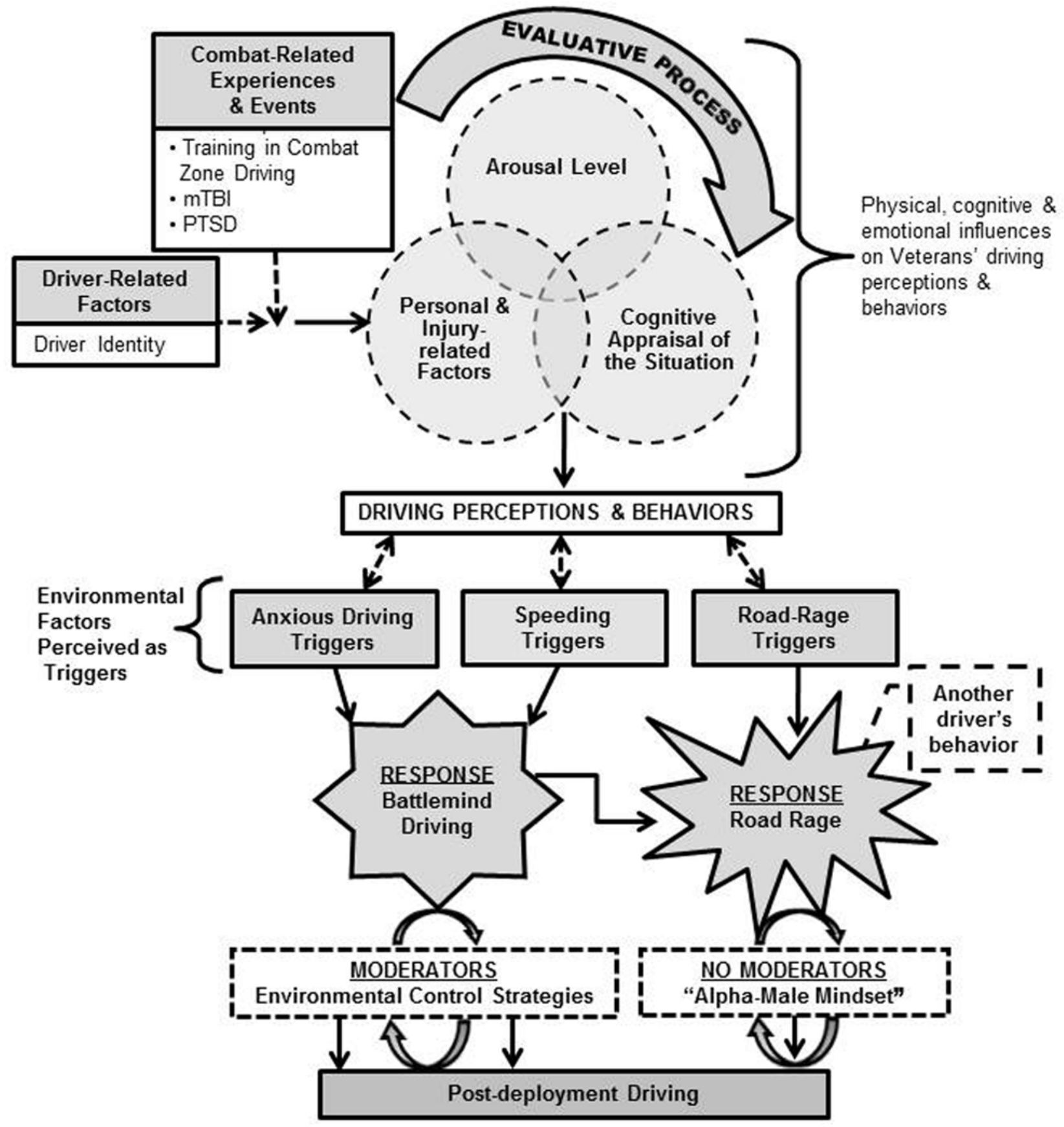

Figure 2.

Conceptual framework illustrating factors affecting driving behavior among combat Veterans with mild traumatic brain injury (mTBI)/ posttraumatic stress disorder (PTSD).

in the environment), problems concentrating, anger outbursts, irritability, and exaggerated startle responses [26]. In the following passage, Veteran 26 discussed how his arousal level affected his driving:
After I get done with [driver's] training, it's weird, like I'm in a really, really calm state and I drive super slow and . . . like I just drive under the speed limit, and just stay to myself, and get in 


\begin{tabular}{|l|l|l|}
\hline Anxious Driving Triggers & Speeding Triggers & Road Rage Triggers \\
\hline Big trucks & Driving long distances & Being cut off/pulled in \\
Crowds & "Need to get off the road" & front of \\
Highways and traffic & Functional deficits & Being forced off road \\
Driving small vehicle & Inattention & Unsafe passing \\
Loud or distracting noises & Fear of getting hit & Being followed too closely \\
Roadside objects & Overpasses & \\
Certain vehicles (Opels \& & Intersections & \\
Bongo trucks) & & \\
Construction zones & & \\
Driving in dark & & \\
Getting lost & & \\
Rain & & \\
\hline
\end{tabular}

\section{Figure 3.}

Veterans' perceived triggers for unsafe driving.

the slow lane and just go. But before training and stuff, [I'm] just kinda . . . a lot more hyper and kinda ... the music affects me a lot too. If I listen to some of this, a lot more ... like you know ... I can’t put Kenny Loggins' "Danger Zone” on 'cause I think I'm Tom Cruise in Top Gun.

According to Veteran 26, participating in calming activities before he drives helps him remain calm and focused while on the road. Conversely, if he hasn't engaged in calming activities he feels "a lot more hyper." Veteran 26 further recognized the impact that music has on his mood, indicating that certain kinds of music or songs increase his arousal level. He used the example of "Danger Zone," a popular song from a 1986 movie about fighter pilots. If he heard that particular song while driving, Veteran 26 implied that he would drive the same way that Tom Cruise's character, Maverick, handled his jet during training-fearlessly dodging and attacking "enemy" aircraft. For Veteran 26, the road became his danger zone. The fact that Veteran 26 actively evaluated his experiences was evident from his words, suggesting that he maintained insight regarding his driving behavior.

Whereas Veteran 26 attributed his speeding to hyperarousal, Veteran 27's interview provided evidence of the opposite. He attributed his speeding to inattention. When asked about his history of collisions, Veteran 27 explained, "Well, yeah not any accidents, but I've had some pretty close calls and you know just where sometimes I just don't pay attention. I just ... just you know, I don't pay attention, I just go faster than what I should. I've got a couple speeding tickets.” For Veteran 27, his inability to pay attention or focus, a common symptom of TBI and PTSD, contributed to speeding and citations.

Functional deficits. While the need to get off the road was closely tied to Veterans' anxiety/arousal levels, our data revealed that Veterans' injury-related functional deficits also contributed to speeding. When discussing his history of speeding citations, Veteran 27 explained:

I even tried to tell a cop one time, I said, "You know, my foot got stuck on the accelerator pedal" and he said, "Well you know, maybe you shouldn't be driving." That excuse didn't work. Well, actually, I use my l-right . . . err, yeah my left foot. Sometimes, yeah 'cause my ankle, my ankle ... has been bothering me for about the last 6 months, it's just been sore and swollen and I don't know why. So I had that [accelerator] adapted for a left foot . . . . But I couldn't, could not get used to it . . . even though I do [it] with my left foot I just ... uh, have a real hard time ... get-you know goin' from left to hit the brakes on the right.

For Veteran 27, speeding was not a careless mistake; it was a consequence of an impairment that affected his 
functional ability to manage his gas and brake pedals with his left foot. Despite having a vehicle modification, Veteran 27 reported his lower-limb impairment affected his ability to brake and contributed to his speeding violations.

\section{Road Rage Triggers}

Veterans attributed road rage triggers to the actions of other drivers. We asked each Veteran participant whether he or she had experienced road rage. Veteran 24 and Veteran 27 immediately responded affirmatively. Veteran 23 and Veteran 26 answered that they became angry or frustrated and yelled at other drivers, but were uncertain whether their behavior qualified as road rage. Veteran 25 required clarification regarding the definition of road rage. He was told by the OT/CDRS that "Road rage is the point where we're yelling in the car, or actually confronting people; sometimes you hear of people actually getting out of their vehicle.” Veteran 25 then replied that he hasn't confronted anyone, but did become frustrated and yell curse words at other drivers.

Being cut off/pulled in front of. Having another driver pull in front of you or being cut off in traffic was a recurrent theme. When asked what leads her to road rage-like behavior, Veteran 23 answered, "When they [other drivers] pull out in front of me . . . 'cause I'm scared that I won't be able to stop. Half the time I don't even see 'em. And then I get right up on them.” For Veteran 23, an admitted speeder, the fear of crashing into a driver who has suddenly pulled in front of her caused her frustration when driving.

Unsafe passing. This theme was associated with a judgment about whether the driving environment was conducive to passing. In this segment, Veteran 27 explained why unsafe passing led him to road rage, stating, “. . . passing me when it's, when it's dangerous to pass you know, stuff like that just ... cu-cause it always takes me back to the accident I was in when I was in the military, you know when we rolled the Humvee . . . you know I just always ... don't wanna be put in that position again.” Veteran 27 associated unsafe passing with a rollover accident while deployed. We do not know for certain that Veteran 27's rollover was caused by a vehicle attempting to pass in dangerous circumstances. However, the memory of the rollover caused him to be vigilant when in traffic.

Being forced off the road. Unlike previous examples, Veteran 26's description of his road rage trigger was characterized by personal confrontation. He explained:
I get angry sometimes ... coming back from the VA and there was a big hay truck with these two dudes in it. And I'm sitting there and they literally ... just moved over and forced me off the side of the road. I was like, "What the hell is your problem?” He was like, "Fuck you!” So I was like, “Okay. Well, get out of the truck!” So, I pulled over. The two got out. I kicked my shoes off and I was like, "I'll kick your ass!" Two big guys ... two big old country fed farmers . . . if I feel like I'm pushed in a scenario-like when those guys ran me off the road. They purposefully did it. They were trying to hurt me ... that's the impression I took, that they were trying to hurt me. They said, "Pull over" and I was like, you know, I might challenge them . . . instead of before, you get mad and you yell at somebody. Now it's, “Okay. Well, I'm going to hurt you!”

Veteran 26's perception of being forced off the road by the truck drivers set off a series of angry, aggressive confrontations. Veteran 26 felt he was literally pushed off the road by the truck drivers. Veteran 26's words also indicated that he felt emotionally "pushed" by them. He believed that the drivers acted "purposefully," with the intent of hurting him. Veteran 26 felt he was targeted, so he reacted by fighting back. This aggressive reaction was new for Veteran 26.

\section{Characterizing Battlemind Driving and Road Rage}

Our data provided numerous examples of Battlemind driving and a compelling example of road rage. For coding and analysis purposes, we operationally defined Battlemind driving as Veterans' descriptions of driving as they were taught to drive in the combat zone. We defined road rage as descriptions of shouting or becoming angry while driving. In the following examples, we use data from Veteran 24 to characterize Battlemind driving and road rage.

To illustrate Battlemind driving, we return to Veteran 24's flashback incident when he locked his brakes in the middle of an interstate. Veteran 24 elaborated, “. . . [ [for] the vehicle that was hit, we gotta set up a perimeter . . . and then assess the ... damage, and then recuperate the [microphone distortion] fallen soldiers ... and if we can't get the uh, vehicle ... we destroy the vehicle." Veteran 24's explanation clarified that locking his brakes was part of a detailed protocol for responding when a military vehicle was hit by an IED. This example illustrated how 
Veteran 24's driving was influenced by combat-zone skills and training.

In the next example, Veteran 24 related how his Battlemind training affected his driving postdeployment. He explained, "I still find myself you know like ... driving in the middle of the road ... [on] the double yellow line. Because that's the way we drove .... I mean that's what we did, you know. We made the road and we made everything else move. And if they got within . . . if they didn't want to move ... we rammed 'em." Driving in the middle of the road was a strategic maneuver to avoid roadside bombs and better monitor other vehicles by keeping them to the rear. Although Veteran 24 implied that driving down the middle of the road was not caused by any specific triggers, but rather, from force of habit, he associated this behavior with his combat-zone driving experiences.

Data from Veteran 24's interview also provided an example of road rage. When asked how he expressed road rage, Veteran 24 answered, "Power-brake* my truck. [7 s pause]. So it boils white smoke. So I go through tires pretty good ... I keep Tire Kingdom ... you know, pretty much well stocked with tires for my truck. Yeah ... and the horn don't do nothing." Veteran 24 tried to intimidate drivers who angered him by causing his tires to smoke and squeal; a behavior that also reflected his driver identity—a racer.

\section{Environmental Control Strategies}

Data indicated that Veterans attempted to manage their driving-related anxieties and behaviors using a number of strategies to control the environment in terms of the road and vehicle driven. These strategies served as moderators to reduce Veterans' stress and enhance Veterans' perception of safety (e.g., paying extra attention to other cars and road features). Road-control strategies included avoiding driving, letting a family member drive, staying near home, choosing specific routes including low-traffic back roads, and being alert to their surroundings. Vehicle-control strategies included using calming music, quieting passengers in high-stress situations (e.g., construction zones), regulating speed with cruise control, and navigating with a global positioning system.

\footnotetext{
*Term refers to applying the vehicle's brakes while accelerating, and then suddenly releasing the brakes to cause the tires to spin, burn, smoke, and squeal. The term is also known as brake torquing.
}

\section{Alpha Male Mindset: Justification for Road Rage}

Unlike Battlemind driving, data did not provide evidence of moderators for road rage. Instead, data provided an intriguing example of how one Veteran used learned norms of military culture to justify his road rage. In the following exchange, Veteran 26 responded to interviewer questions regarding his experiences with road rage.

Veteran 26: I get, I get defensive pretty quick. Um, it's, it's weird like I mean, I think it's uh, once again, it comes down from the war. Like you're used to . . . you can't put yourself in a scenario that's going to force you to be like pushed 'cause it takes away from-I mean, especially when you're a leader, like, when you're a squad leader, you have to make certain decisions and they always said you know, "Right or wrong, you make a decision.” You know 'cause if you don't make any decisions, it's definitely wrong. So you react. And it's just kind of like learned behavior ....

Interviewer: So it's a learned response .... .

Veteran 26: Yeah, I mean, you gotta learn how to be the alpha male. Especially if you're going to be the leader - you've gotta be the most dominant one there so you can lead your troops. If they question you, then you're in trouble so that behavior kind of passes over.

Veteran 26 attributed his road rage behaviors to military training that taught him how to establish himself as an alpha male. The term alpha refers to group leaders that have the highest social status. Veteran 26 described an alpha male as dominant, in control, prepared to fight, and capable of making decisions or reacting without hesitation. Alpha male characteristics are typically viewed positively in combat. Veteran 26 realized he was reverting to alpha male behaviors when driving, contributing to road rage. While aware, notably, he does not discuss efforts to control or manage these behaviors.

\section{Overview of Conceptual Framework}

The preliminary conceptual framework illustrates that driver-related factors were affected by combatrelated experiences and events. Together, these factors and events affect the Veterans' physical, cognitive, and emotional domains of experience. In Figure 1, overlapping circles represent interconnectedness among the three domains of experience. Our data indicated that Veterans are aware of these changes and evaluate their 
change-related experiences. We illustrate this concept through use of an arching arrow to border the circles. Our data further suggest that Veterans' perceptions of their changing physical, cognitive, and emotional experiences influence their driving perceptions and behaviors.

The framework also shows that Veterans predominantly perceived environmental factors as triggers to their driving behavior. Specifically, our data revealed that Veterans identified anxious driving triggers, speeding triggers, and road rage triggers. Veterans' perceptions of these triggers further informed their driving perceptions and, ultimately, their behavioral responses. Our data demonstrated that driving-anxiety triggers and speeding triggers contributed to Battlemind driving, while road rage triggers led to road rage behaviors. Data indicated that Battlemind driving is moderated by Veterans' coping strategies, whereas road rage is not moderated. Data provided one example of how a Veteran attempted to justify his road rage behavior using learned norms of military culture - the alpha male mindset. The last component of the framework designated that changes in driving behavior from pre- to postdeployment are influenced by "moderated” Battlemind driving and road rage.

We defined driver-related factors as the individual characteristics of the Veteran driver. Drawing from social sciences theory, we considered this category to include the Veteran's demographic influences (i.e., age, race/ethnicity, sex, educational/vocational history, military background, and socio-economic status), behaviors, personality traits, social-environmental influences, cultural perspectives, and life history. A primary subtheme of driver-related factors was driver identity.

We defined combat-related experiences and events as military service-related occurrences that affected the ability of Veterans to function in their previous social roles such as spouse, parent, friend, or worker. Based on the OIF/OEF literature, this category included events that led to injury such as blast exposures and training or experience with combat-zone driving.

Regarding the Veteran's interconnected physical, cognitive, and emotional experiences, we defined the physical level of experience as the Veteran's personal and injury-related factors. From our data, for example, we learned that Veteran 27 had a right leg amputation and decreased sensation and movement in his left leg. These issues and their effect on Veteran 27's driving were captured by the theme functional deficits and were described under the category of speeding triggers.
Drawing from the OIF/OEF literature and stress and coping theory [27-29], we defined the Veteran's cognitive level of experience as his or her appraisal of the driving situation at-hand. Veterans with mTBI and/or PTSD face challenges with organization, planning, and memory-related tasks [30-34]. Deficits in these areas affect driver performance, especially as demands of the driving task increase [35-36]. For example, the cognitive level of experience may influence how accurately Veterans are able to assess and respond to road safety threats or navigate a new route when encountering a detour.

The Veteran's emotional level of experience represented his or her feelings and emotions while driving, including feelings of arousal or excitability. Research suggests that arousal and hypervigilance are part of the range of symptoms associated with PTSD [37-38]. The Veteran's arousal level equally emerged as a relevant theme in our data.

\section{Supporting Theories}

Michon's model of driver behavior [35] and stress and coping theories [27-29] informed our themes and broader findings. Michon's model categorizes driving behavior into three levels: strategic, tactical, and operational. Strategic behaviors are the result of conscious thought and planning that occurs before driving (e.g., deciding not to drive at night). Tactical behaviors involve conscious decisions leading to motor responses and vehicle control maneuvers (e.g., handling on a sharp curve). Operational driving behavior related to car control is a result of subconscious rather than overt decisions (e.g., lane maintenance). Identifying the level of a behavior can assist in planning interventions, which are best targeted at the strategic and tactical levels. Deployment experiences (including predeployment driver training) and driving in combat situations may influence driving at all three levels. On the strategic level, Veterans reported planning their driving (e.g., selecting routes and/or driving at a time of day when they were more likely to encounter low traffic). On the tactical level, some Veterans continued to consciously employ driving maneuvers learned in combat in an effort to reduce perceived threats and relieve driving anxiety [39]. On an operational level, the persistence of combat driving behaviors in the postdeployment period may be in part due to the fact that these driving behaviors (e.g., speeding or straddling the center of the road) have become habit [39]. 
Stress or anxiety and related impacts on physiological arousal may be an important factor in driving performance, especially in regards to alertness and attention [35-36]. Based on stress and coping theory [27-28], Gage, an occupational therapist, developed the appraisal model of coping to guide interventions for clients who reported difficulty coping with stressful situations [29]. In the model, primary appraisal is a person's determination of a situation or stressor as to whether it is "harmful, threatening, challenging, beneficial, or of no importance" [29, p. 354]. Secondary appraisal is when the person assesses his or her resources for coping with the stressor, which can be physical, psychological, social, or material [29]. For any situation, the person's decision about how to react (coping plan) results from primary and secondary appraisal and the assessment of resources [29].

\section{DISCUSSION}

To our knowledge, this study is the first to apply grounded theory methods to examine the perspectives of OIF/OEF combat Veterans with mTBI/PTSD and develop a conceptual framework of factors underlying their driving behavior. Using this approach, we found that Veterans' experiences offered a rich context for identifying factors and processes that may contribute to Battlemind driving and road rage. For instance, we found that some Veterans in our sample (Veterans 23 and 24) upheld a distinct sense of driver identity that reflected their driving habits prior to deployment and that this identity may change (Veteran 23) or be reinforced (Veteran 24) by deployment experiences. Additionally, Veterans openly described their driving habits postdeployment, including the triggers that influenced their anxious driving, speeding, and road rage. We found that Veterans attempted to manage their driving-related anxieties and behaviors through strategies to control road and vehicle environments. These strategies served to moderate anxious driving and speeding, improve Veterans' perceptions of their driving safety, and help them avoid citations (e.g., speeding). Data indicated, however, that despite the use of strategies, Veterans continued to drive aggressively. Use of strategies was not evident in the road rage data. Instead, one interview (Veteran 26) revealed that learned norms of military culture (i.e., the alpha male mindset) may underlie road rage.
Overall, our Veterans' descriptions of driving behaviors learned in combat (e.g., altered lane position or speeding) and executed postdeployment were consistent with driving behavior described in prior studies of aggressive driving among combat Veterans [9,11-13,15]. While our data illustrated tendencies toward aggressive driving and road rage, our findings differed in that data also revealed nonaggressive driving behaviors related to anxiety or stress. These behaviors included anxietymanagement strategies used by Veterans to control their road and vehicle environments (i.e., avoiding crowded roads). Veterans described some behaviors as planned responses, but described other behaviors as automatic responses they linked to prior experiences (e.g., blast exposure).

Although definitions of aggressive driving and road rage vary widely across the social and behavioral sciences [40], the use of grounded theory methods enabled us to consider concepts of aggressive driving and road rage from a specific context, the experiences of five OIF/ OEF Veterans with mTBI/PTSD. We found Michon's model particularly relevant to the data and gave examples of how Veterans' driving behaviors were influenced at strategic, tactical, and operational levels [35]. Moreover, our Veterans' experiences, concerns, and use of strategies reflected findings from a study of civilian drivers with mTBI [41]. By comparison, the influence of PTSD was noteworthy in our study and was characterized by Veterans' descriptions of unique driving stressors (e.g., concern for IEDs, loud noises triggering flashbacks, or increased anxiety in crowded driving situations). However, other symptoms Veterans described overlapped between PTSD and TBI, such as inattention (e.g., failing to notice cars) or impulsivity (e.g., being easily provoked to aggressive driving).

Our findings suggest that Veteran participants engaged in an ongoing process of behavioral adaptation and coping as they drove. Veterans' descriptions of appraising situations and responding with varied driving behaviors and strategies reflected the stress and coping models addressed previously [27-29]. Specifically, the appraisal model of coping showed how adaptation processes and the nature and severity of combat experiences influenced Veterans' postdeployment driving [29]. This adaptation process over time is echoed by other authors $[9,42]$, who note an increased risk of crash and injury for drivers who fail to adapt their driving. Knapik et al. suggest mortality rates will decline over time and risky 
behavior will decrease as part of readaptation for returning combat Veterans [42]. Others have suggested this process can be facilitated through identification of highrisk or sensation-seeking Veterans and provision of behavioral or medical interventions [43].

Study limitations include a small sample size $(N=5)$, drawn from one site, and only one female participant. While we gained an in-depth understanding of the driving experiences of our Veteran participants, findings should not be generalized to Veterans outside our sample. Any future qualitative studies should include a larger sample that is diverse in gender and ethnicity to capture a wider range of Veteran experiences. Due to the small sample size, we did not achieve theoretical saturation or redundancy of data. However, repetition of many themes and concordance with the existing literature was evident. Given the richness of the data, our pilot findings and "preliminary conceptual framework" could inform future studies. A final limitation was the use of a predefined set of interview questions that did not specifically address factors known to contribute to impaired driving, namely fatigue, sleep issues, medication use, and recreational drug/alcohol use [39].

Our findings hold implications for clinical education and, in combination with the findings from the Classen et al. study [5], for developing a randomized controlled trial to test driving intervention strategies. Our findings, together with results of similar Veteran-specific driving studies $[4-5,8,11-13,15,44]$, can be used to tailor interventions such as the VA's driver rehabilitation program or the Department of Defense/VA health promotion/injury prevention campaigns among others. Tailoring to address the individualized driving needs of Veterans with mTBI and PTSD, for example addressing hypervigilance from a fear of roadside bombs or suspicious vehicles, may improve intervention outcomes.

Regarding future research directions, we are extending this research through a current study [44]. Larger qualitative studies that capture additional Veterans' experiences could further inform our framework. Identifying who is susceptible based on predeployment factors such as personality (e.g., risk tolerance) and/or deployment factors (e.g., time deployed, exposures to traumatic events) is important for ensuring that appropriate and sufficient resources are available postdeployment for Veterans most in need of services. Due to the multitude of risk (e.g., combat exposure, driving exposure) and protective factors (e.g., personality, predeployment health status) that may contribute to stress, anxiety, PTSD, or persistent sequela from mTBI, a clear link between those factors, medical conditions, and driving has not been established [38].

\section{CONCLUSIONS}

Grounded theory methods were useful for capturing the driving experiences of combat Veterans with mTBI/ PTSD. Veterans in our sample were insightful about their driving experiences and readily identified factors that influence their driving behavior. Veterans offered reasons for their driving behavior, explained the impact of combat-related driving on current driving behaviors, and identified triggers that led to anxious driving, aggressive driving, and road rage. Veterans reported using environmental control strategies to manage their driving behaviors, but may benefit from tailored strategies to manage them more effectively. Intervention and outcomes studies are needed to comprehensively address the driving needs of returning veterans with mTBI/PTSD.

\section{ACKNOWLEDGMENTS}

\section{Author Contributions:}

Contributed qualitative data analysis and interpretation:

E. M. Hannold.

Primary preparation of manuscript: E. M. Hannold.

Chief writing contribution to Methods, Findings, and Conclusions

sections: E. M. Hannold.

Edited Introduction and Discussion sections: E. M. Hannold.

Development of initial conceptual framework and table:

E. M. Hannold.

Principal investigator of primary study: S. Classen.

Contributed to study design: S. Classen.

Provided de-identified qualitative data: S. Classen.

Writing contribution to Introduction and Methods sections:

S. Classen.

Guidance and critical editing of manuscript: S. Classen.

Contributed primary and critical literature reviews: S. Winter.

Assistance with data interpretation: S. Winter.

Writing contribution to Introduction, Findings, and Discussion

sections: S. Winter.

Critical review and editing of entire manuscript: S. Winter.

Conducted interviews: D. N. Lanford.

Contributed verification of transcripts: D. N. Lanford.

Critical review of manuscript: D. N. Lanford.

Co-investigator of primary study: C. E. Levy.

Facilitated recruitment: C. E. Levy.

Contributed critical editing of manuscript: C. E. Levy.

Financial Disclosures: All authors have declared that no competing interests exist. 
Funding/Support: This material was based on work supported by the NF/SG Malcom Randall VA Medical Center (project VA 00066678; PI: Classen). The Institute for Mobility, Activity, and Participation at University of Florida's College of Public Health and Health Profession is also gratefully acknowledged for providing infrastructure.

Additional Contributions: We thank doctoral student, Zamarys Roman, OTR/L, for her contributions to the literature review for this manuscript. Dr. Classen is now Professor and Director of the School of Occupational Therapy, Elborn College, London, Ontario, Canada. Effective October 1, 2013, the Rehabilitation Outcomes Research Center Research Enhancement Award Program at the NF/SG VAHS was funded as the VA Center of Innovation on Disability and Rehabilitation Research, Veterans Integrated Service Network 8 (CINDRR), Gainsville Division.

Institutional Review: Our project was granted approval by the University of Florida's IRB and the NF/SG VAHS's Human Research Protection Program prior to all research activities.

Participant Follow-Up: As part of the informed consent process, participants agreed to use of their interview data for publication purposes. Therefore, we do not intend to notify participants of the study publication.

\section{REFERENCES}

1. American Occupational Therapy Association. Driving and community mobility statement. Am J Occup Ther. 2010;64 (Suppl):S112-24.

2. Plach HL, Sells CH. Occupational performance needs of young veterans. Am J Occup Ther. 2013;67(1):73-81. [PMID:23245785] http://dx.doi.org/10.5014/ajot.2013.003871

3. Lew HL, Rosen PN, Thomander D, Poole JH. The potential utility of driving simulators in the cognitive rehabilitation of combat-returnees with traumatic brain injury. J Head Trauma Rehabil. 2009;24(1):51-56. [PMID:19158596] http://dx.doi.org/10.1097/HTR.0b013e3181956fe3

4. Lew HL, Amick MM, Kraft M, Stein MB, Cifu DX. Potential driving issues in combat returnees. NeuroRehabilitation. 2010;26(3):271-78. [PMID:20448316]

5. Classen S, Levy C, Meyer DL, Bewernitz M, Lanford DN, Mann WC. Simulated driving performance of combat veterans with mild tramatic brain injury and posttraumatic stress disorder: A pilot study. Am J Occup Ther. 2011;65(4): 419-27. [PMID:21834457] http://dx.doi.org/10.5014/ajot.2011.000893

6. Classen S, Wang Y, Winter SM, Velozo CA, Lanford DN, Bédard $\mathrm{M}$. Concurrent criterion validity of the safe driving behavior measure: A predictor of on-road driving outcomes. Am J Occup Ther. 2013;67(1):108-16.

[PMID:23245789]

http://dx.doi.org/10.5014/ajot.2013.005116
7. Stern E, Prudencio T, Sadler E. Shifting gears: Helping service members return to the road. OT Practice. 2011; 16(2):6-7.

8. Armed Forces Health Surveillance Center (AFHSC). Deaths while on active duty in the U.S. Armed Forces, 1990-2011. MSMR. 2012;19(5):2-5. [PMID:22694586]

9. Adler AB, Bliese PD, McGurk D, Hoge CW, Castro CA. Battlemind debriefing and battlemind training as early interventions with soldiers returning from Iraq: Randomization by platoon. J Consult Clin Psychol. 2009;77(5): 928-40. [PMID:19803572] http://dx.doi.org/10.1037/a0016877

10. United Services Automobile Association (USAA). Returning warriors driving safety report [Internet]. San Antonio (TX): USAA; 2012. 3 p. Available from:

https://content.usaa.com/mcontent/static assets/Media/ Returning Warriors report summary.pdf

11. Sayer NA, Noorbaloochi S, Frazier P, Carlson K, Gravely A, Murdoch M. Reintegration problems and treatment interests among Iraq and Afghanistan combat veterans receiving VA medical care. Psychiatr Serv. 2010;61(6): 589-97. [PMID:20513682] http://dx.doi.org/10.1176/appi.ps.61.6.589

12. National Research Council: Committee on Gulf War and Health. Gulf War and health: Volume 7: Long-term consequences of traumatic brain injury. Washington (DC): The National Academies Press; 2008.

13. Kuhn E, Drescher K, Ruzek J, Rosen C. Aggressive and unsafe driving in male veterans receiving residential treatment for PTSD. J Trauma Stress. 2010;23(3):399-402. [PMID:20564373]

14. Kraft M, Amick MM, Barth JT, French LM, Lew HL. A review of driving simulator parameters relevant to the Operation Enduring Freedom/Operation Iraqi Freedom veteran population. Am J Phys Med Rehabil. 2010;89(4):336-44. [PMID:20299851] http://dx.doi.org/10.1097/PHM.0b013e3181d3eb5f

15. Lew HL, Kraft M, Pogoda TK, Amick MM, Woods P, Cifu DX. Prevalence and characteristics of driving difficulties in Operation Iraqi Freedom/Operation Enduring Freedom combat returnees. J Rehabil Res Dev. 2011;48(8):913-25. [PMID:22068370] http://dx.doi.org/10.1682/JRRD.2010.08.0140

16. Warden D. Military TBI during the Iraq and Afghanistan wars. J Head Trauma Rehabil. 2006;21(5):398-402. [PMID:16983225] http://dx.doi.org/10.1097/00001199-200609000-00004

17. Military Health System Office of Strategic Communications. DOD numbers for traumatic brain injury (2012 Q3 Report of Defense Medical Surveillance System (DMSS) \& Theater Medical Data Store (TMDS) data). Washington 
(DC): Defense and Veterans Brain Injury Center (DVBIC); 2012.

18. Hill JJ 3rd, Mobo BH Jr, Cullen MR. Separating deployment-related traumatic brain injury and posttraumatic stress disorder in veterans: Preliminary findings from the Veterans Affairs traumatic brain injury screening program. Am J Phys Med Rehabil. 2009;88(8):605-14.

[PMID:19620825]

http://dx.doi.org/10.1097/PHM.0b013e3181ae0f83

19. Collins C. PTSD and TBI: Where we are now. Defense Media Network [Internet]. Tampa (FL): Faircourt Media Group; 2014 [updated 2011 Dec 1]. Available from: http:// www.defensemedianetwork.com/stories/ptsd-and-tbi-wherewe-are-now-2/

20. National Center for PTSD. DSM criteria for PTSD [Internet]. Washington (DC): Department of Veterans Affairs; 2013 [updated 2012 Dec 6; cited 2013 Jan 8]. Available from: http://www.ptsd.va.gov/professional/PTSD-overview/ dsm5 criteria ptsd.asp

21. Brenner LA, Vanderploeg RD, Terrio H. Assessment and diagnosis of mild traumatic brain injury, posttraumatic stress disorder, and other polytrauma conditions: Burden of adversity hypothesis. Rehabil Psychol. 2009;54(3):239-46. [PMID:19702422] http://dx.doi.org/10.1037/a0016908

22. Glaser BG, Strauss AL. The discovery of grounded theory: Strategies for qualitative research. New York (NY): Aldine DeGruyter; 1967.

23. Strauss A, Corbin J. Basics of qualitative research: Techniques and procedures for developing grounded theory. 2nd ed. Thousand Oaks (CA): SAGE Publications; 1998.

24. Charmaz K. Constructing grounded theory: A practical guide through qualitative analysis. London (UK): SAGE Publications; 2006.

25. Miles MB, Huberman AM. An expanded sourcebook: Qualitative data analysis. 2nd ed. Thousand Oaks (CA): SAGE Publications; 1994.

26. American Psychiatric Association. Diagnostic and statistical manual of mental disorders. Revised 4th ed. Washington (DC): American Psychiatric Association; 2000.

27. Lazarus RS, Folkman S. Stress, appraisal and coping. New York (NY): Springer Publishing Company, Inc; 1984.

28. Lazarus RS. Stress and emotion: A new synthesis. 1st ed. New York (NY): Springer Publishing Company, Inc; 2006.

29. Gage M. The appraisal model of coping: An assessment and intervention model for occupational therapy. Am J Occup Ther. 1992;46(4):353-62. [PMID:1566801] http://dx.doi.org/10.5014/ajot.46.4.353

30. Okie S. Traumatic brain injury in the war zone. N Engl J Med. 2005;352(20):2043-47. [PMID:15901856]

http://dx.doi.org/10.1056/NEJMp058102
31. Tanielian T, Jaycox I. Invisible wounds: Mental health and cognitive care needs of America's returning veterans. In: Tanielian T, Jaycox I, editors. Invisible wounds of war: Psychological and cognitive barriers, the consequences, and services to assist recovery. Santa Monica (CA): RAND Corporation; 2008.

32. Sayer NA, Rettmann NA, Carlson KF, Bernardy N, Sigford BJ, Hamblen JL, Friedman MJ. Veterans with history of mild traumatic brain injury and posttraumatic stress disorder: Challenges from provider perspective. J Rehabil Res Dev. 2009;46(6):703-16. [PMID:20104400] http://dx.doi.org/10.1682/JRRD.2009.01.0008

33. Hoge CW, McGurk D, Thomas JL, Cox AL, Engel CC, Castro CA. Mild traumatic brain injury in U.S. Soldiers returning from Iraq. N Engl J Med. 2008;358(5):453-63. [PMID:18234750] http://dx.doi.org/10.1056/NEJMoa072972

34. Nelson LA, Yoash-Gantz RE, Pickett TC, Campbell TA. Relationship between processing speed and executive functioning performance among OEF/OIF veterans: Implications for postdeployment rehabilitation. J Head Trauma Rehabil. 2009;24(1):32-40. [PMID:19158594] http://dx.doi.org/10.1097/HTR.0b013e3181957016

35. Michon JA. A critical view of driver behavior models: What do we know, what should we do? In: Evans L, Schwing, RC, editors. Human behavior and traffic safety. New York (NY): Plenum Press; 1985.

36. Brookhuis KA, de Waard D. Assessment of driver's workload: Performance and subjective and physiological indexes. Stress, workload, and fatigue. Mahwah (NJ): Lawrence Erlbaum Associates; 2001.

37. Kashdan TB, Elhai JD, Frueh BC. Anhedonia and emotional numbing in combat veterans with PTSD. Behav Res Ther. 2006;44(3):457-67. [PMID:16446151] http://dx.doi.org/10.1016/j.brat.2005.03.001

38. Lemaire CM, Graham DP. Factors associated with suicidal ideation in OEF/OIF veterans. J Affect Disord. 2011;130 (1-2):231-38. [PMID:21055828] http://dx.doi.org/10.1016/j.jad.2010.10.021

39. Zamorski MA, Kelley AM. Chapter 5: Risky driving behavior. In: Psychological aspects of deployment and health behaviours. Neuilly-sur-Seine (France): Research and Technology Organisation, North Atlantic Treaty Organisation (NATO); 2012. Report No. TR-HFM-164.

40. Smart RG, Mann RE. Is road rage a serious traffic problem? Traffic Inj Prev. 2002;3(3):183-89. http://dx.doi.org/10.1080/15389580213643

41. Bottari C, Lamothe MP, Gosselin N, Gélinas I, Ptito A. Driving difficulties and adaptive strategies: The perception of individuals having sustained a mild traumatic brain injury. Rehabil Res Pract. 2012;2012:837301. 
JRRD, Volume 50, Number 10, 2013

[PMID:22448334]

http://dx.doi.org/10.1155/2012/837301

42. Knapik JJ, Marin RE, Grier TL, Jones BH. A systematic review of post-deployment injury-related mortality among military personnel deployed to conflict zones. BMC Public Health. 2009;9:231. [PMID:19594931] http://dx.doi.org/10.1186/1471-2458-9-231

43. Killgore WD, Cotting DI, Thomas JL, Cox AL, McGurk D, Vo AH, Castro CA, Hoge CW. Post-combat invincibility: Violent combat experiences are associated with increased risk-taking propensity following deployment. J Psychiatr Res. 2008;42(13):1112-21. [PMID:18291419] http://dx.doi.org/10.1016/j.jpsychires.2008.01.001

44. Florida Institute on Disability and Rehabilitation and Florida Trauma Rehabilitation Center for Returning Military Personnel. Efficacy of a Driving Intervention Program on Safe Community Mobility for Combat Veterans [Internet]. Gainsville (FL): University of Florida, 2014. [updated
2012 Oct 25; cited 2013 Mar 7]; Available from: http://fidr.phhp.ufl.edu/resources/brochures/

Submitted for publication April 5, 2013. Accepted in revised form June 11, 2013.

This article and any supplemental material should be cited as follows:

Hannold EM, Classen S, Winter S, Lanford DN, Levy CE. Exploratory pilot study of driving perceptions among OIF/OEF Veterans with mTBI and PTSD. J Rehabil Res Dev. 2013;50(10):1315-30.

http://dx.doi.org/10.1682/JRRD.2013.04.0084
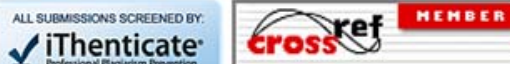